\title{
A TIRA COMO NOTÍCIA: UM EXERCÍCIO DE APLICAÇÃO DA TEORIA MULTIFATORIAL DO JORNALISMO
}

\author{
Comic strip as news story: an exercise in applying the Multifactorial Theory of \\ Journalism
}

\section{La tira mientras que las noticias: un ejercicio de aplicación de la Teoría Multifactorial del Periodismo}

José Antonio Meira da Rocha

Professor na Universidade Federal de Santa Maria - UFSM/Cesnors

joseantoniorocha@gmail.com

Liége Schilling Copstein

Mestra em Literatura Comparada pela Universidade Regional Integrada do Alto Uruguai e das

Missões - URI/FW

liegecopstein@gmail.com

\begin{abstract}
Resumo
O objetivo deste estudo é investigar a possibilidade da ressignificação da tira de jornal subgênero das histórias em quadrinho - sob o conceito de notícia proposto pela Teoria Multifatorial desenvolvida por Jorge Pedro Sousa. Para tanto, traçamos uma analogia entre esta proposta teórica e a forma como a Teoria Literária e os estudos culturais vêm consolidando o gênero HQ como obra portadora de literariedade, a partir de pressupostos como o do Sistema Literário, de Antonio Candido, e as observações de Umberto Eco e Marshall McLuhan sobre o gênero quadrinhos, além de traçar a trajetória da tira desde seu surgimento, relacionando-a com o advento do jornalismo popular no final do século 19 . Também foi avaliado o papel do gênero quadrinhos tanto na representação de questões sociais como na constituição de um veículo preferencial do pensamento não hegemônico, constituindo-se assim "notícia" se tomado pelos parâmetros da pós-modernidade.
\end{abstract}

Palavras-chave: Teoria Multifatorial da Notícia. Literatura. Quadrinhos.

\begin{abstract}
This paper aims to investigate the possible ressignification of the comic strip - a sub gender of the comics - under the news story concept proposed by the Multefactorial Theory of Journalism, by Jorge Pedro Sousa. To do do, an analogy was drawn between this theoretical proposal and how the Theory of Literature and the cultural studies are consolidating the comics gender as a valid mean for expressing literariness. Our arguments are based on the propositions of Literary System by Antonio Candido, and the studies of Umberto Eco and Marshall McLuhan on the comics gender, besides drawing the path of comic strip, since its appearance, related to the outcome of popular journalism at the end of the 19th century. We also assessed the role of comics as gender in both the representation of social issues as the establishment of comics as a suitable vehicle for not hegemonic thinking, thus seen as "news" if taken by the parameters of postmodernity.
\end{abstract}


Keywords: Multifactorial Theory of News. Literature. Comics.

\section{Resumen}

El objetivo de este estudio es investigar la posibilidad de resignificación de la historieta de la prensa gráfica - subgénero historieta - a partir del concepto de noticia propuesto por la Teoria Multifactorial desarrollada por Jorge Pedro Sousa. Para ello, trazamos una analogía entre esta propuesta teórica con la Teoria Literária y cómo los estudios culturales vienen consolidando el género historieta como una obra portadora de literariedad a partir de presupuestos como el de Sistema Literário, de Antonio Candido, y las observaciones de Umberto Eco y Marshall McLuhan sobre el género cómic, además de trazar la trayectoria de la tira desde su surgimiento, en relación con el advenimiento del periodismo popular en el siglo XIX. También fue avaliada la función del género historieta tanto en la representación de cuestiones sociales como en la constitución de un vehículo preferencial de pensamiento no hegemónico, formando así "noticias" para ser adoptada por los parámetros de la posmodernidad.

Palabras-clave: Teoria Multifactorial de la Noticia. Literatura. Historieta.

\section{INTRODUÇÃO}

O que é notícia? Esta inquietação fundamental que permeia todo o desenvolvimento da Teoria do Jornalismo, desde seus primeiros estudos em meados no século XIX, tem encontrado diversas respostas que na maioria das vezes se complementam e mais raramente se excluem. Porém, só há relativamente pouco esses mesmos estudos culminaram na elaboração de uma teoria mais alinhada com o modelo de pensamento descentralizado e relativista que caracteriza nosso tempo, a Teoria Multifatorial da Notícia (2005), trabalhada principalmente pelo pesquisador português Jorge Pedro Sousa. Sousa percebe os processos e forças que agem para definir o que é notícia como as partes interativas de um sistema, de certa forma "metabolizando" as principais propostas de abordagens teóricas anteriores, e integrando-as para construir um novo pressuposto sobre o tema.

Nesse sentido, a abordagem multifatorial proposta pelo autor pode ser comparada, em nossa opinião, a processo análogo observado na evolução da Teoria Literária, cuja questão primordial é "o que é literatura". E cabe mesmo relacioná-la ao conceito de "sistema literário" cunhado por Antonio Candido (1959), onde os elementos do trinômio escritor/obra/sociedade são vistos como coagentes na produção do texto de literatura, e na percepção do que é literatura, a partir, como propõe o autor, de certos "denominadores comuns":

Estes denominadores são, além das características internas (línguas, temas imagens), certos elementos de natureza social e psíquica, embora literariamente organizados, que se manifestam historicamente e fazem da literatura aspecto orgânico da 
civilização. Entre eles se distinguem: a existência de um conjunto de produtores literários, mais ou menos conscientes do seu papel; um conjunto de receptores, formando os diferentes tipos de público, sem os quais a obra não vive; um mecanismo transmissor, de(modo geral, uma linguagem, traduzida em estilos), que liga uns a outros. $\mathrm{O}$ conjunto dos três elementos dá lugar a um tipo de comunicação inter-humana, a literatura, que aparece, sob este ângulo, como sistema simbólico, por meio do qual as veleidades mais profundas do indivíduo se transformam em elementos de contato entre os homens, e de interpretação das diferentes esferas da realidade (CANDIDO, 1959, p. 17).

Isto porque o advento do pós-estruturalismo, a consolidação de um olhar crítico, também ele, de certa forma "multifatorial" sobre o texto, trouxe-nos ao momento presente da teoria literária, onde quase se pode substituir a indagação inicial, “o que é literatura?”, por outra: o que, afinal, NÃO é literatura?

A percepção do gênero história em quadrinhos como obra literária exemplifica bem, segundo cremos, esse alargamento de fronteiras no que diz respeito ao estabelecimento de cânones que permeia todas as grandes questões acadêmicas contemporâneas, e leva-nos a indagar, como motivação deste estudo, se a tira de quadrinhos do jornal não poderia igualmente ser percebida, sob os parâmetros mais recentes da teoria do jornalismo representado pela Teoria Multifatorial, como notícia.

Assim como a teoria literária tem dado conta de que, no espaço de um formato narrativo até poucas décadas apreendido como gênero menor que é a $H Q$, podem residir elementos da mais alta literariedade, porque no espaço igualmente insuspeito da tira, tido atualmente como elemento extrajornalístico dentro do corpus do jornal, não poderiam residir as especifidades que fazem de uma notícia o que ela é? Não poderiam seus temas, sua estrutura, sua linguagem, veicular informações que no final das contas, se referem a tudo que é, conceitualmente, compreendido como notícia, constituindo "um relato integral de um fato que já eclodiu no organismo social” (MARQUES DE MELO, 1985, p. 49).

Construção textual híbrida, imagética e verbal, a trajetória da história em quadrinhos enquanto gênero ilustra o próprio processo de reconfiguração de paradigmas inaugurado pelos meios de comunicação de massa. Porém, mais ainda a tira, como embrião de todo o formato "quadrinhos", guarda particularidades que motivaram este estudo, sendo a principal delas sua inserção no campo do jornalismo. Antes de mais nada, devemos entender como a tira se diferencia em meio à variedade de subgêneros compreendida sob a denominação "histórias em quadrinhos". 
Para Scott McCloud (2008), tiras são "juxtaposed pictorial and other images in deliberate sequence"1. Ele considera a sequência, ou a narrativa imagética, como o coração dos comics ${ }^{2}$. H. C. Harvey, no entanto, vê a mistura de informação verbal (texto) e imagem como a principal característica das tiras (2010). Já Moacy Cirne define a tira como um comic veiculado em jornal, onde o autor constrói o ritmo visual em um espaço limitado, em dois, três ou quatro planos (1977, p. 43), diferentemente da revista, onde os quadros podem libertar-se desta rigidez. Assim, de forma bem simplificada, a tira é a narrativa em HQ que deve desenrolar-se no espaço de no máximo quatro ou cinco quadrinhos, o que lhe confere limitações e potencialidades específicas.

A primeira tira caracterizada como tal - arte pictórica sequencial impressa, dotada de características formais específicas, como os quadrinhos e o balão que abriga o texto - foi publicada inicialmente de forma intermitente em 1894 no jornal New York World. Ela narrava as aventuras do Yellow Kid, personagem principal do universo ficcional criado pelo desenhista Richard Felton Outcault. A partir do ano seguinte, ganharia espaço fixo na publicação.

O protagonista circulava pela comunidade fictícia de Hogan's Alley, caracterizada como um bairro proletário tanto pela aparência dos personagens e as situações em que se desenrolavam as tramas quanto - principalmente - pela linguagem marcada pela gíria e léxico associado à classe trabalhadora da época. $\mathrm{O}$ enredo em geral retratava a vida cotidiana sob o viés cômico. Após pouco tempo, em 1899, a tira Yellow Kid deixaria de ser publicada em jornal, continuando como revista independente por mais alguns anos.

Seguiram-se outras tiras, notadamente Katzenjammer Kids ou Captain and the Kids, desenhada por Rudolph Dirks para o New York Journal a partir de 1897, a qual no Brasil ficou conhecida como Os sobrinhos do Capitão. Alguns autores creditam a Dirks o uso pioneiro do balão para texto, o que daria a Katzenjammer Kids precedência sobre Yellow Kid como primeira tira da história, se forem consideradas as publicações em veículos não jornalísticos. Ao contrário da existência efêmera daquela, Katzenjammer Kids - que narrava as aventuras de dois meninos endiabrados, Hans e Fritz - continuou sendo desenhada até 1979.

Já Bringing up father, desenhada a partir de 1913 por George McManus, que no Brasil receberia o nome de Pafúncio e Marocas, merece destaque por representar um panorama da estratificação social da época na sociedade americana. As narrativas desenvolvem-se em torno

\footnotetext{
Justaposição de pictogramas e outras imagens em uma sequência deliberada.

2 Para efeito de fluência e clareza, usaremos alternadamente as expressões em inglês comics (para quadrinhos em geral), comic book (revista de história em quadrinhos) e comic strip (tira), além da abreviação em português já popularizada, HQ.
} 
do cotidiano do casal Jiggs e Maggie (ele um imigrante irlandês que enriqueceu da noite para o dia ao receber um grande prêmio nas corridas de cavalos, ela o equivalente da época à contemporânea "alpinista social", sempre preocupada em ser aceita no seio da alta sociedade, apesar da origem proletária).

Vale mencionar também Krazy Cat, entre as primeiras tiras a instituir protagonistas animais como estratégia de representação figurada para abordar uma questão bastante humana e que permanece em pauta desde sempre: a dos afetos perversos. Desenhada por George Herriman para o New York Journal a partir de 1913, e transformada em desenho animado mais tarde, Krazy é uma gata perdidamente apaixonada pelo rato Ignatz, que não lhe retribui o sentimento. Pelo contrário, Ignatz dedica seu tempo a frustrar os avanços de Krazy, arremessando tijolos contra sua cabeça, ao que ela sempre retruca com o bordão que encerra cada "aventura": "Meu querido Inácio...".

Publicadas eventualmente como "calhau" - expressão que no jargão jornalístico designa material de menor interesse e conteúdo atemporal, do qual se lança mão para preencher espaços que restam vagos após a diagramação das notícias e anúncios (RABAÇA; BARBOSA, 1978, p. 68) - as tiras acabaram migrando rapidamente para um veículo específico, os comic books, ou revistas de histórias em quadrinhos, e dando origem a narrativas mais extensas. É dessas narrativas mais longas que se ocupam principalmente os estudos literários e culturais, e portanto observaremos sua trajetória como objeto da teoria literária antes de retomarmos a tira e seu veículo original, o jornal.

\section{QUADRINHOS ENQUANTO LITERATURA}

Se o aparecimento da tira no final do século XIX marcou o nascimento de uma nova linguagem, destinada a conquistar os segmentos sociais iletrados para o florescente jornalismo de apelo popular, a premiação com o Pulitzer em 1992 da história em quadrinhos Maus, a Survivor's Tale, de Art Spiegelman, instituiu um novo marco na evolução desse gênero. É curioso notar que a HQ apareceu pela primeira vez no jornal New York World de propriedade do mesmo Joseph Pulitzer que instauraria a premiação pouco antes de morrer, em 1911, com objetivo de estimular a produção no campo da literatura, música e jornalismo.

Pulitzer certificou-se de que os estatutos da premiação, gerida pela Universidade de Columbia, permitissem a alteração, inclusão ou extinção de categorias de indicação, demonstrando sensibilidade ao perceber que o conceito de gêneros narrativos canônicos não 
poderia ser estático. Foi essa medida que permitiu a Maus ser o primeiro comics agraciado na história do prêmio, o que definitivamente validaria essa forma de expressão como arte.

Lançada inicialmente em sua versão integral em 1986, a obra conta na verdade duas histórias, sobre dois panos de fundo diversos, ambas autobiográficas: a tumultuada relação do autor com seu pai, Vladek Spiegelman, judeu polonês sobrevivente do campo de concentração nazista de Auschwitz, e o relato do próprio Vladek sobre os eventos vivenciados por ele durante a Segunda Guerra Mundial na Europa. A premiação adicionou mais uma dimensão ao debate sobre a possível profundidade reflexiva oportunizada por textos veiculados no formato comic book, e também consolidaria o subgênero graphic novel, sobre o qual cabe uma contextualização.

Ao entregar à editora os originais de sua obra A Contract with God, and Other Tenement Stories, em 1978, o renomado quadrinista Will Eisner a apresentou sob a denominação graphic novel (no Brasil, romance gráfico ou novela gráfica), por julgar que o conceito ligado ao gênero comic book não era capaz de abranger toda a proposta, e que não haveria interesse do editor por uma "simples" história em quadrinhos. Em sua palestra durante o Will Eisner Symposium: The 2002 University of Florida Conference on Comics and Graphic Novels, Eisner afirmou:

I'm here to tell you that I believe strongly that this medium is literature. It's a form of literature, and it's reaching its maturity now. [...] The word "comics," of course, we're still living with, is a misnomer. We can't get rid of the thing. We can't get rid of it-it's like "Kleenex." It doesn't belong here and it's partly our fault because comics originally were designed to be funny stories. They were originally called "the funnies" and called "the jokes," and later on "the comicals. [...]The future of the medium now hinges - hangs - on the support of the academic world because in order for the medium to grow and mature as it has been, it needs the attention and the interest of people who, in the academic world, are able to dissect it, to discuss it, to recognize it, and to evaluate it, which will establish a standard that young comic artists coming into the field will aspire to. (EISNER, 2002) . $^{3}$

Vemos que a suposição de que os comic books não são um formato "nobre" o suficiente para veicular assuntos "adultos" norteia a própria gênese da denominação graphic novel. De forma geral, considera-se graphic novel uma narrativa pictórica sequenciada e de enredo autônomo, abordando temas complexos com certo grau de sofisticação e

3 Estou aqui para dizer que acredito fortemente que este meio é literatura. É uma forma de literatura, e está atingindo sua maturidade agora. [...] A palavra "comics", é claro, ainda a utilizamos, mas é um equívoco. [...] Não podemos livrar-nos dela, é como "Kleenex". Ela não cabe aqui e é em parte culpa nossa, porque quadrinhos originalmente foram projetados para ser histórias engraçadas. Eles foram originalmente chamados de "engraçados" e de "piadas", e, mais tarde, "os cômicos". [...] O futuro do meio agora depende do mundo acadêmico, porque para que cresça e amadureça como está acontecendo, é necessária a atenção e o interesse de pessoas que, no mundo acadêmico, são capazes de dissecá-lo, discuti-lo, reconhecê-lo e avaliá-lo, o que irá estabelecer um padrão ao qual jovens artistas de quadrinhos iniciantes irão aspirar. 
aprofundamento reflexivo, e frequentemente apresentadas em volumes de qualidade editorial superior (capa dura, impressão de alta resolução, papel durável, etc...).

A necessidade de criar uma expressão que diferenciasse as histórias em quadrinhos "sérias" dos outros representantes do gênero parece emanar da mesma convicção observada em relação a seu veículo de origem, o jornal popular; os quadrinhos não se prestariam a oportunizar reflexão ou informar de forma efetiva sobre o que está acontecendo na sociedade, mesmo que um olhar mais interessado possa provar o contrário, como veremos continuando a observar o florescimento dos quadrinhos como gênero.

Poucas décadas após seu surgimento, o fenômeno dos comic books havia alcançado tal significância nos Estados Unidos em meados da década de 1940 que entre 80 e 100 milhões de exemplares de revistas eram vendidos semanalmente. Como a cultura da leitura do comic book inclui a troca ou empréstimo de exemplares, a estimativa era de que cada exemplar vendido atingia de seis a dez leitores, o que tornava seu público superior ao do cinema, rádio e demais publicações. Segundo Hadju, no início da década de 1950, 650 títulos eram publicados de forma regular mensalmente (2008).

Se o Yellow Kid havia sido criado para atingir as camadas proletárias, iletradas mas ávidas pelo status de consumidores de informação, e reproduzia seu universo (como demonstraremos no próximo segmento), o ofício de desenhar quadrinhos seduzia artistas originários dessas mesmas classes populares, notadamente imigrantes, que viam nessa forma de expressão um canal possível para sua concepção da realidade, uma mundivisão tomada a partir das trincheiras das classes excluídas; eles eram “...members of racial, ethnic, and social minorities who turned to comics because they thought of themselves or their ideas as unwelcome in more reputable spheres of publishing and entertainment"*4 (HADJU, 2008).

Aconteceu, porém, que não apenas os excluídos, mas os jovens da classe média americana do momento pós-guerra, viram na estética do comics a forma de posicionar-se dialeticamente em relação à velha ordem. Para Hadju, foram os quadrinhos, e não o rock ' $n$ ' roll, a forma de expressão artística que representou, se não fomentou, toda a contracultura da segunda metade do século 20. A temática dos comics a partir da década de 1950, longe de restringir-se ao universo pueril, começou a ocupar-se da science fiction, do humor negro, do terror, da criminalidade e da violência como estética de contestação, e veio a reação. 4 “...membros de minorias raciais, étnicas ou sociais que se voltaram para o comics porque percebiam a si
próprios ou a suas ideias como indesejáveis em esferas editoriais e do entretenimento mais conceituadas. 
PROGRAMA DE PÓS-GRADUAÇÃO EM COMUNICAÇÃO DA UNIVERSIDADE FEDERAL DE SANTA MARIA

É então que se inicia a ofensiva da cultura hegemônica contra os quadrinhos, representada notadamente pela publicação em 1954 do ensaio Seduction of the Innocent (2004) pelo psiquiatra Fredric Werthan. Denunciando uma influência nociva e desestabilizadora das HQ sobre todo o status quo a partir da adesão dos jovens, Werthan afirmaria: "I think Hitler was a beginner compared to the comic book industry." (WERTHAN apud HADJU, 2008).

Vamos encontrar o comics contemplado, ainda que de forma tangencial, em textos fundadores do pensamento contemporâneo como A Indústria Cultural: o Esclarecimento como Mistificação das Massas, de Theodor Adorno e Max Horkheimer. Os autores ocupam-se principalmente da produção cinematográfica americana como forma de reprodução massiva de produtos culturais de baixa oportunização reflexiva, categoria em que se incluem os desenhos animados, arte cuja evolução vamos encontrar exatamente a partir da sofisticação tecnológica no manejo da imagem que propiciou uma nova configuração das representações pictóricas quadro a quadro que constituem a história em quadrinhos. Basta lembrar um brinquedo clássico do início do século XIX: o livrinho contendo imagens sequenciais que quando manuseadas com certa velocidade forjam a ilusão de movimento.

Adorno e Horkheimer afirmam: "Os filmes de animação eram outrora expoentes da fantasia contra o racionalismo. Eles faziam justiça aos animais e coisas eletrizados por sua técnica, dando aos mutilados uma segunda vida..." (1985, p. 114). Os autores ressentem-se daquilo que observam, em sua época, como uma intensificação artificial do ritmo da narrativa pontuado apenas por representações de experiências sensoriais referentes ao plano concreto quedas, impactos, correrias, movimentos rotatórios - onde a banalização da violência remete à aceitação da violência capitalista: “Assim como o Pato Donald nos cartoons, assim também os desgraçados na vida real recebem a sua sova para que os espectadores possam se acostumar com a que eles próprios recebem.” (1985, p. 114).

A nova perspectiva sobre a indústria cultural proposta pelo pós-estruturalismo, notadamente a partir da década de 1960, porém, percebe potencialidades criativas menos estáticas e mais instigantes no gênero quadrinhos, como veremos em Umberto Eco (2001). O autor analisa ponto a ponto os elementos textuais e construções pictóricas dos quadrinhos, reconhecendo-os como linguagem, como semântica própria, ainda que híbrida, de potenciais criadores restritos apenas pelas limitações de seu suporte.

5 “Acho que Hitler era um principiante comparado à indústria das histórias em quadrinhos". 
Eco aplicaria pressupostos similares aos de Roland Barthes quanto à ressignificação ao identificar, no comics Steve Canyon, "elementos de uma iconografia que, mesmo quando nos reporta a estereótipos já realizados em outros ambientes (o cinema por exemplo), usa de instrumentos gráficos próprios do 'gênero'." Para o autor, "esses elementos iconográficos compõem-se numa trama de convenções mais ampla, que passa a constituir um verdadeiro repertório simbólico, e de tal forma que se pode falar numa semântica da estória em quadrinhos.” (ECO, 2001, p. 144-145).

O elemento fundamental dessa semântica identificada por Eco - e por todos os estudiosos do comics depois dele - é o balão, o espaço gráfico dentro do quadrinho que abriga o texto e designa, através de uma extensão afilada apontada em direção ao personagem desejado, quem está "falando". Esta "extensão" do balão assume outras configurações conforme se quer representar tipos de elocução: uma fileira de bolinhas quando se trata de "pensamento" ou diálogo interior, bordas em forma de serra para representar fúria ou outra emoção extrema, e assim por diante. Estas são convenções gráficas, evidentemente, partilhadas por todos os leitores habituais de quadrinhos e incorporadas à nossa cultura de massa, como "referência a um determinado código." (ECO, 2001, p. 145).

Se em Eco a linguagem do comics recebe atenção em seus elementos narrativos dentro do campo linguístico e semiótico, outra obra clássica da época ocupou-se novamente das possíveis mensagens subliminares e ideológicas contidas em um dos mais populares personagens de quadrinhos do século XX. Para ler o Pato Donald (DORFMAN; MATTELART, 2010), obra de encomenda da esquerda chilena da década de 1970 para denunciar o imperialismo norte-americano, retoma as preocupações de Adorno e Horkheimer com relação à função "alienadora" do gênero, desta vez porém concedendo-lhe intensidade ideológica insuspeita até então. Esses estudos principiaram lançar um olhar mais interessado sobre o gênero, que vinha de estar relegado alternadamente ou à inocuidade de uma proposta estética superficial ou à demonização de ideologia desestabilizadora da nova ordem mundial pós-guerra, ou Guerra Fria.

O já referido cenário de reconfiguração dos estudos culturais inaugurado na década de 1960, que veio lançar os primeiros olhares realmente interessados sobre a arte do quadrinho, é o mesmo que fermentou a formação de um dos mais aclamados autores de tiras no Brasil, o quadrinista Laerte Coutinho, ou apenas Laerte, como assina. Ele iniciou sua carreira em pleno período da ditadura militar brasileira, em 1970. Era também o período em que a contracultura, 
fenômeno de inspiração pós-moderna que atingiu seu auge nos EUA na década de 60, chegava ao Brasil e era metabolizado em movimentos como a Tropicália, e o "desbunde".

Pacifismo, ecologia, liberdade sexual e de expressão, experimentações em áreas tão variadas como a vivência em comunidades alternativas e as "viagens" lisérgicas buscando autoconhecimento através de percepções alteradas da realidade, o novo orientalismo enaltecido do qual os Beatles foram precursores em suas viagens à Índia, a literatura marginal, a imprensa alternativa, os festivais de rock ao ar livre e os próprios quadrinhos undergroundatravés do trabalho, por exemplo, do americano Robert Crumb $^{6}$ - eram algumas das ideias e tendências atreladas ao fenômeno.

Desde o início, portanto, a trajetória de Laerte esteve marcada por um momento e cenário cultural que reproduzia as propostas da estética e do pensamento pós-modernos. Essa inserção confirmou-se no decorrer de sua carreira. Os primeiros anos estão marcados pela atuação na resistência à repressão política, a década pós AI-57 . Laerte trabalhou em 1974 na campanha eleitoral do MDB - Movimento Democrático Brasileiro, o partido único de oposição ao regime militar - e nos anos seguintes colaborou sucessivamente em diversos veículos alvejados pela censura do regime, inclusive o legendário jornal $O$ Pasquim.

Simultaneamente aos trabalhos em veículos de resistência, Laerte também publicaria na imprensa hegemônica, culminando com seu ingresso no quadro fixo da seção de tiras do jornal Folha de São Paulo em 1991. A visibilidade oferecida por esse veículo de grande alcance e referencial no jornalismo brasileiro foi definitiva para sua consolidação entre os maiores artistas de HQ no país, e a partir daí, Laerte tem sido responsável por trazer ao espaço do jornal questões que bem poderiam, citando novamente Marques de Melo, ser considerada notícia enquanto "um relato integral de um fato que já eclodiu no organismo social" (2003). Por exemplo, a questão do crossdresser.

Em 2009, após a perda do filho em acidente automobilístico e o final de seu terceiro casamento heterossexual, Laerte surpreendeu o público ao assumir sua homossexualidade e a

6 Robert Crumb tornou-se célebre a partir do final dos anos 1960 por veicular, em sua obra, uma crítica feroz ao modo de vida norte-americano. Seu trabalho, fortemente identificado com a cultura hippie, conquistou novos espaços para a história em quadrinhos, tornando-se icônico da contracultura. A cantora Janis Joplin era grande fã de seu trabalho e convidou-o para ilustrar a capa de alguns de seus álbuns musicais.

7 Ato Institucional $\mathrm{n}^{\circ}$ 5, conjunto de medidas restritivas institucionalizado pelo governo militar em 1968 que autorizava diversas ações repressivas, como a censura aos meios de comunicação e a cassação de direitos políticos. Sua justificativa era deter os elementos "subversivos" que comprometiam o andamento da "Revolução de 64", tal como os militares denominavam o golpe pelo poder realizado naquele ano. 
opção pelo comportamento crossdresser $^{8}$ : passou a vestir-se permanentemente de acordo com o código de indumentária feminina. Em entrevista à revista TRIP, afirmou:

Eu sou militante. Eu faço parte de uma associação, da Abrat (Associação Brasileira de Transgêneros), e a gente tá aí pra isso, pra discutir e estimular o debate. Justamente pra que as pessoas percam o medo de se reconhecer como transgêneras, como transexuais, como homossexuais, ou o que for. Para as pessoas não se sentirem ridículas, erradas, bizarras, como o ponto de vista conservador faz questão que elas se sintam. (TRIP..., 2013).

Essa postura que desafia os conceitos de gênero e outros critérios classificatórios como índices identitários - raça, credo, classe - vem sendo representada pelo artista de forma intensa em diversas tiras publicadas nos últimos anos na Folha de São Paulo.

Em 2012, por exemplo, após sua adesão ao crossdressing, Laerte foi vítima de comportamento discriminatório no banheiro de uma pizzaria em São Paulo. O caso ganhou destaque na mídia e oportunizou discussões sobre a reavaliação das práticas cotidianas e instituídas que dizem respeito às delimitações de gênero. $\mathrm{O}$ episódio foi referenciado pelo desenhista em várias tiras, como a seguinte, publicada no Blogay (blog vinculado ao espaço online do jornal Folha de São Paulo), onde se autorretrata9:

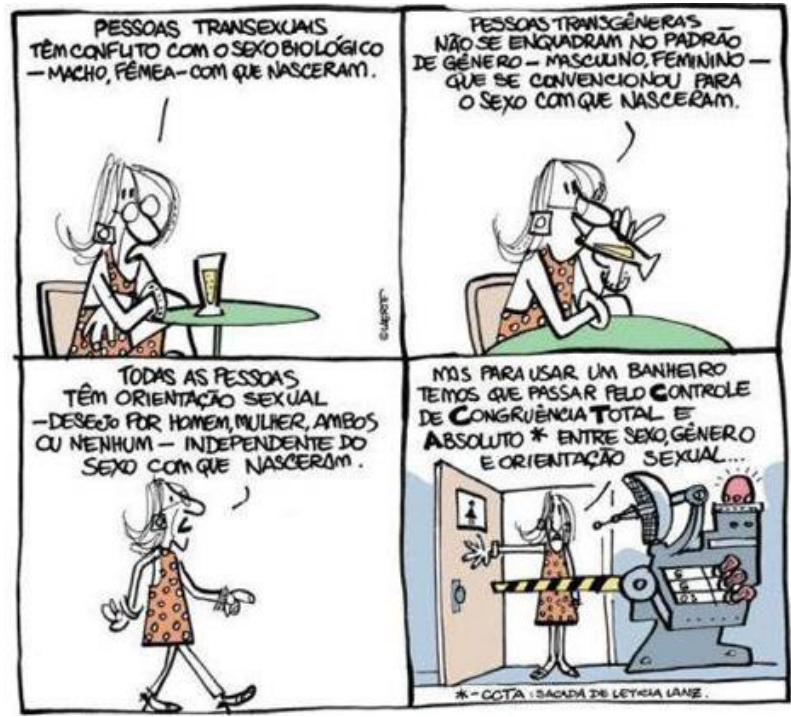

(LAERTE apud ANGELO, 2012)

Ao levar a temática do crossdressing ao espaço das tiras do jornal, entendemos que Laerte reveste aquele espaço de um conteúdo noticioso. Evidentemente, esse conteúdo só é noticioso ao tomarmos como parâmetro os pressupostos sistêmicos de "o que é notícia"

8 "Crossdresser" refere-se à pessoa que veste-se "ao contrário"; ao contrário das expectativas e convenções associadas a seu gênero.

9 Considerando que este estudo toma a história em quadrinhos como gênero literário híbrido, consideramos essencial a citação textual inserida no contexto pictórico que constitui a obra em análise. 
revelado pela Teoria Multifatorial da Notícia, e é em busca dessa fundamentação que se desenvolve o próximo segmento.

\section{A TIRA ENQUANTO NOTÍCIA}

Antes de mais nada, é preciso lembrar o que é jornalismo, ou a técnica de produzir e divulgar notícias. Do ponto de vista histórico, a prática do jornalismo remonta à antiguidade; como a própria retórica, como o próprio discurso, como a própria linguagem que não podem ser descoladas da condição humana, também existem os fenômenos pré-jornalísticos que se confundem a todo momento com a prática da literatura e remontam ao início da civilização. Aliás, cabe lembrar desde já que o binômio objetividade/subjetividade tem sido o principal referencial regulador da diferença na prática dessas linguagens, referencial esse que o pensamento contemporâneo na área das ciências humanas vem colocando em cheque.

Rapidamente, lembremos que as próprias ilustrações rupestres narrando a vida cotidiana dos homens pré-históricos - que estão entre os mais antigos registros de cultura humana e são frequentemente percebidos como histórias em quadrinhos primitivas - podem ser interpretadas tanto como arte pictórica, como narrativa protoliterária, como registro histórico e também como relato jornalístico, dependendo da abordagem que se imprima à análise. Mais tarde, as Actas romanas vieram a ser consideradas os primeiros "jornais”, num sentido amplo (RIZZINI, 1977, p. 4). Já na Idade Média, as crônicas dos andarilhos, as cartas e os relatos de viagens esboçavam um desejo de "reportar", que foi impulsionado pelo evento da tipografia de Gutenberg.

O jornalismo moderno começa a delinear-se ainda no século XVII, com modelos diversos na França e na Inglaterra, e a partir do século seguinte o evento do Iluminismo e do humanismo racional lançam as bases do conceito da objetividade que nortearia a experiência jornalística norte-americana, fundadora dos pressupostos que marcam fortemente, ainda hoje, a despeito de todas as teorias pós-estruturalistas, a prática jornalística contemporânea. A missão do jornalista é, de antemão, impossível: buscar a imparcialidade e a verdade absolutas, sabendo hoje que estas não existem em termos absolutos (SOUSA, 2008, p. 82-83).

O século XIX - na virada do qual surge a tira - abriga eventos históricos e socioculturais que explicam e condicionam o que Jorge Pedro Sousa define como "o jornalismo na maioridade" (2008, p. 100-103). Entre eles, o autor lista a expansão e consolidação do capitalismo e da Revolução Industrial, com os consequentes fortalecimento do sistema bancário, concentração populacional nos grandes centros urbanos, reconfiguração 
da família no modelo nuclear urbano contemporâneo e o aumento da oferta de tecnologia e de bens e serviços.

Ao crescimento dos centros urbanos, associado à industrialização, seguiram-se a necessidade/oportunidade de ascensão social e educacional dessas populações; o ensino básico gratuito disseminou-se pela necessidade de mão de obra qualificada que a nova ordem econômica e produtiva exigia, mas essa nova classe operária, por sua vez, demandaria, a partir de então, a satisfação de necessidades antes restritas à burguesia. De posse de mais conhecimento, essa nova classe força a democratização da vida política e sua inserção nos processos decisórios da coletividade, com o sucesso, por exemplo, dos movimentos sufragistas universais.

A participação política e o acesso ao conhecimento, conquistados por essa nova classe trabalhadora, influenciaram na formação de grandes correntes ideológicas que criaram as condições para as grandes guerras do século XX, como o conceito e a prática do nacionalismo originado da consolidação dos estados, o positivismo científico que alimentou noções que degenerariam para o racismo e o antissemitismo. Por outro lado, a gênese dos movimentos pela igualdade social - resultado do acesso da classe trabalhadora ao questionamento crítico oportunizou o surgimento do pensamento de esquerda em todos os seus matizes.

Essas novas "verdades", tomando a si próprias cada qual como única, num modelo de pensamento ainda afeito ao humanismo racionalista predominante, culminaram com a eclosão e massificação dos conflitos armados, como resultado, de um lado, do acirramento do processo de imposição dessas novas ideologias, e de outro, da tecnologia bélica resultante tanto dos avanços científicos como das necessidades do mercado armamentista. Todos esses fatores influenciaram na "transfiguração da imprensa e das relações entre jornalismo e política" (SOUSA, 2008, p. 103), que se deu entre as duas metades do século XIX e sobre a qual cabe um olhar mais detalhado.

Nas primeiras décadas desse período, o campo jornalístico podia ainda ser comparado a uma evolução dos "clubes de cavalheiros" dos séculos anteriores, palco de debate de ideias e ideologias direcionado aos segmentos pensantes da sociedade e seus partidos. Era, afirma Sousa, um espaço das “...elites cultas, com alto poder econômico, alfabetizadas e envolvidas na vida política e econômica ..." (2008, p. 103).

Porém, a partir de meados daquele século, a nova classe trabalhadora forjada pelos processos descritos acima foi gradualmente conquistando sua participação no espaço público que incluía a imprensa. "Os cidadãos, consumidores, contribuintes e votantes, necessitavam 
de uma imprensa que ecoasse os seus problemas e desejos, reflectisse os seus modos de vida e desse resposta às suas necessidades informativas" (SOUSA, 2008, p. 103).

É nesse momento que surge nos Estados Unidos a imprensa de massas, a penny press o nome se refere ao baixo preço dos exemplares e opõem-se à party press, a imprensa partidária e elitista - jornais de grande apelo popular e nenhum constrangimento em assumirse como produto, idealizados por empreendedores como William Randolph Hearst (The New York Journal) e Joseph Pulitzer (New York World). A rivalidade entre os veículos de Pulitzer e Hearst, e suas respectivas estratégias empresariais, interligam-se à própria história da tira:

\begin{abstract}
A primeira coisa que Hearst fez para tornar o jornal competitivo foi recrutar um vasto número de colaboradores do World de Pulitzer, incluindo R.F. Outcault, o célebre criador do Yellow Kid, a primeira história em quadrinhos do mundo, que começou a publicar-se no World, em tiras diárias, em 1896 (de onde advém, aliás a alcunha "imprensa amarela" com que foi brindada a segunda geração da imprensa popular)(SOUSA, 2008, p. 149).
\end{abstract}

Assim, vemos que o fenômeno do surgimento da tira no espaço do jornal coincide com marcos evolutivos do próprio jornalismo, determinados por fatores históricos. Retomemos alguns deles, para observar como estão representados nessa forma de narrativa: o personagem protagonista do Yellow Kid - que também atendia pelo nome de Michael Dugan - vaga pelas ruas de um bairro pobre operário, expressando-se em linguagem de gueto repleta de gíria e expressões idiomáticas e vestindo apenas uma camisola esfarrapada, descalço, com os cabelos raspados como se, observam alguns autores, tivesse acabado de passar por um surto de piolhos ${ }^{10}$.

Embora aparentemente se trate de um menino, a família de Dugan/Yellow Kid nunca aparece. Essa era a realidade da maioria das crianças dos bairros operários, deixadas à própria sorte enquanto seus pais trabalhavam nas fábricas, ou relegadas à orfandade quando estes sucumbiam à violência urbana ou aderiam às muitas gangues, compostas principalmente por imigrantes irlandeses, italianos e asiáticos, assim como afro-americanos. Esses segmentos de excluídos, condenados à miséria e marginalidade, acabavam recrutados para a criminalidade na cidade de Nova York na virada do século XIX, especialmente a partir da favela Five Points, na região da ilha de Manhattan hoje conhecida como Little Italy, célebre também pelos abatedouros municipais. Sobre Five Points, o historiador Robert McNamara afirma:It was said to be the roost of gang members and criminals of all types, and was particularly known as the home turf of flamboyant gangs of Irish immigrants. The reputation of the Five Points was

10 Os piolhos, transmissores de tifo, eram causa constante de epidemias nas zonas pobres dos grandes centros urbanos - assim como cólera, difteria e tuberculose -, cuja gravidade numa época anterior ao desenvolvimento dos antibióticos bem se pode imaginar. 
so widespread that when the famous author Charles Dickens visited New York, the chronicler of London's underside wanted to see it for himself. ("Five Points Neighborhood in New York City", [s.d.]).

De fato, Charles Dickens dedicaria a Five Points um capítulo inteiro de seu relato da viagem, American Notes for General Circulation, onde reproduz a visita tendo como cicerones e seguranças dois policiais. Assim ele descreve o local:

\begin{abstract}
Poverty, wretchedness, and vice, are rife enough where we are going now. [...] What place is this, to which the squalid street conducts us? A kind of square of leprous houses, some of which are attainable only by crazy wooden stairs without. What lies beyond this tottering flight of steps, that creak beneath our tread? A miserable room, lighted by one dim candle, and destitute of all comfort save that which may be hidden in a wretched bed. Beside it, sits a man: his elbows on his knees, his forehead hidden in his hands. 'What ails that man?' asks the foremost officer. 'Fever', he sullenly replies, without looking up. Conceive the fancies of a feverish brain, in such a place as this! [...] Where dogs would howl to lie, women, and men, and boys slink off to sleep, forcing the dislodged rats to move away in quest of better lodgings. (DICKENS, 2009).
\end{abstract}

Todo esse cenário extremamente violento é retratado também no ensaio "The gangs of New York: an informal history of the underworld", publicado em 1928 por Herbert Asbury (2008), que inspirou o filme Gangs of New York, do cineasta americano Martin Scorsese.

Percebe-se, portanto, que a tira não apenas teve papel determinante na caracterização do jornalismo moderno, como oferecia conteúdo informativo e crítico mais abrangente e instigante do que sua qualificação como narrativa ligeira, de entretenimento infantil, parecia sugerir. Essa percepção da tira como conteúdo recreativo superficial marcaria por muitos anos o gênero das histórias em quadrinhos, até o advento das graphic novels. Mas que fatos, forças e circunstâncias o condicionaram?

A tira surge num momento em que o jornal passa a ser abordado como produto, como mercadoria que deve agradar ao novo público composto pelas classes populares. Esse novo modelo de jornal opõe-se a outro, o do jornal de elite, o jornal do mundo tido como culto. Sendo a tira uma invenção do jornal popular, cria-se então uma inferência equivocada de que ela pertence ao campo do inculto, do popularesco, do superficial.

Ao mesmo tempo, esses jornais populares assumem um compromisso com a informação enquanto reflexo fidedigno da sociedade, conceito que fundamenta a primeira teoria do jornalismo, surgida de autores diversos em meados da década de 1950: a Teoria do Espelho. Segundo Castro, a Teoria do Espelho propõe que:

O jornalista seria um mediador desinteressado, um observador isento, imparcial, que descreveria objetivamente os fatos. O princípio básico seria a separação de fatos e opiniões. Pregava-se que a palavra poderia refletir a realidade, assim como a 
fotografia, recém inventada. O Jornalismo usaria métodos científicos que evitariam a subjetividade (2013, p. 5).

A valorização da isenção e da objetividade expressa pela Teoria do Espelho representam mais uma vez a reafirmação dos jornais populares diante da imprensa partidária e elitista, e resultaram na percepção da prática do jornalismo como intensamente crítica. Essa percepção deve-se à representação do jornalismo - inclusive e principalmente por autor referenciação - como uma atividade intrinsecamente combativa, igualitária e questionadora, do jornalismo como pilar e indicativo da prática democrática, defensor dos princípios de direito e do livre arbítrio:

\begin{abstract}
O modelo ocidental de jornalismo, cujas raízes radicam no modelo britânico de jornalismo edificado a partir do final do século XVII, alicerçado nos princípios da liberdade de expressão e de imprensa, preconiza que a imprensa deve ser independente do estado e dos poderes, tendo direito a reportar, comentar, interpretar e criticar as actividades dos agentes do poder, inclusivamente dos agentes institucionais, sem repressão ou ameaça de repressão. Teoricamente, os jornalistas são apenas limitados pela lei (tida por justa), pela ética e pela deontologia. O campo jornalístico configura-se, assim, como uma espécie de espaço público, um mercado livre de ideias, onde se ouvem e, por vezes, se digladiam as diferentes correntes de opinião. (SOUSA, 2008, p. 196).
\end{abstract}

A censura à imprensa, ou a implantação de uma imprensa hegemônica estritamente institucional caracterizada como aparelho do estado, costuma estar associada às circunstâncias da vigência de regimes autocráticos. Nem é preciso recorrer ao clássico exemplo da União Soviética na segunda metade do século XX ou ao Brasil do período da ditadura militar; aconteceu aqui também no longínquo ano de 1747, quando a Carta Régia proibia impressão de livros e jornais sob pena de degredo. Por essa razão o primeiro jornal brasileiro - o Correio Braziliense, fundado por Hipólito da Costa - era impresso em Londres e remetido clandestinamente para o país entre 1808 e 1822. Com a declaração da independência, o periódico, de conteúdo declaradamente separatista, encerrou suas atividades.

Mas se quisermos lançar um olhar sobre as próprias origens do jornalismo, notaremos que elas são, por assim dizer, “ideologicamente híbridas". Ficção, informação e propaganda dispensavam contornos definidos nos panfletos que circulavam pelas ruas das principais capitais da Europa desde o século XV, tidos como os primórdios da imprensa moderna; na França pré-revolucionária do século XVIII, intelectuais como Diderot prestavam-se a redigir longas cartas aos nobres entediados retidos em suas propriedades rurais, prestando contas de tudo que acontecia na corte.

Esse "tudo", evidentemente, referia-se ao compreendido pelo horizonte de expectativas da nobreza: mortes, casamentos, fofocas da sociedade, negócios, política... Nada 
tinha a ver com os panfletos subversivos que denunciavam os abusos do poder. O jornalismo, enfim, sempre teve uma agenda, e o esforço por desnudar essa agenda resultou na sua teorização, de base metodológica marcadamente pós-estruturalista. As principais questões que a teoria do jornalismo busca responder são: 1) O que são notícias? 2) Por que as notícias são como são? 3) Quais são os efeitos das notícias? (CASTRO, 2013, p. 4).

Lancemos um brevíssimo olhar sobre algumas das principais propostas teóricas para entendimento do processo jornalístico moderno. Quase cem anos depois da Teoria do Espelho, em 1950, o jornalista David Manning White e o psicólogo Kurt Lewin publicariam o estudo que ficou conhecido como Teoria do Gatekeeper. ${ }^{11}$ Ela parte de um pressuposto que escapou à teoria inicial: o jornal não pode ser o perfeito espelho da sociedade, simplesmente porque é impossível noticiar tudo que acontece, a todos e a todo tempo.

Assim, existe um filtro para determinar o que será noticiado, para avaliar o que é notícia, e, segundo White, a filtragem dependeria unicamente do poder de decisão do jornalista, baseado em critérios pessoais, subjetivos e arbitrários. O problema dessa teoria é que ela atribui exagerado poder decisório ao jornalista, ignorando outras forças em ação no processo de edição.

$\mathrm{Na}$ mesma época, outras teorias atribuiriam o poder decisório a diversos agentes do campo jornalístico; para Warren Breed e sua Teoria Organizacional, por exemplo, a política interna do jornal e sua linha editorial - ou seja, a concepção da empresa de como deve ser o "produto" jornal - contaminam mais ou menos sutilmente os processos decisórios do jornalista sobre o que deve ou não ser considerado notícia. O poder das ideologias na determinação do que é notícia foi considerado nas teorias Estruturalista - as notícias reproduziriam a ideologia hegemônica -, Construcionista - as rotinas que regulam a "construção" das notícias reproduzem condicionamentos linguístico-culturais que também “constroem" a representação da realidade - e na teoria da Ação Política, que se divide entre os que percebem os jornalistas como esquerdistas ou como subjugados pelo pensamento de direita dos diretores dos jornais.

De uma forma ou de outra, o poder de determinar o que é notícia continua nas mãos dos jornalistas ou das empresas jornalísticas de acordo com a teoria seguinte, desenvolvida em 1972 por McCombs e Shaw. A Agenda Setting, ou Teoria do Agendamento, propõe que os assuntos que ocupam a opinião pública são "agendados" pela imprensa, que, de certa forma, induz o público a considerar alguns temas mais relevantes do que outros. Segundo a Agenda

11 Gatekeeper: porteiro. 
Setting, "a mídia ajuda a estruturar no público a imagem da realidade social, a organizar novos elementos dessa mesma imagem, a formar opiniões e crenças novas" (CASTRO, 2013, p. 6).

No final do século XX, ganha adesão a Teoria do Newsmaking, impulsionada por pesquisadores como Mauro Wolf, Nelson Traquina e Gaye Tuchman. Para eles, a poder de decidir o que é ou será notícia está disseminado entre todos que atuam no processo produtivo do jornal, desde os repórteres até os diretores.

\begin{abstract}
O jornalista nem tem o nível de poder individual que lhe é atribuído pela Teoria do Gatekeeper, nem é tão subjugado dentro da redação quanto entende a Teoria Organizacional. A notícia em seu estado final seria resultado da negociação entre vários, de certa forma, gatekeepers, que, a despeito de suas inevitáveis subjetividades individuais, atuariam com base em critérios profissionais de noticiabilidade (CASTRO, 2013, p. 8).
\end{abstract}

Esses critérios profissionais de noticiabilidade são expressos pelo conceito de "valornotícia”, idealizado ainda na década de 1960, que leva em consideração, por exemplo, a quantidade de pessoas afetadas diretamente pelo evento, a sua proximidade com a comunidade a quem se dirigem as notícias, o quanto ele tem de inesperado ou pouco usual, sua proximidade cultural, e assim por diante.

A instituição desses critérios aponta para uma rotinização da prática jornalística que confirma as observações de Umberto Eco acerca do jornalismo contemporâneo, colocando em perspectiva o mito da objetividade e clareza, da verdade acima de tudo. A percepção do campo jornalístico como espaço da verdade e da liberdade é abalado pela percepção do jornal como mercadoria cultural:

\footnotetext{
...o que é um jornal, se não um produto, formado por um número fixo de páginas, obrigado a sair uma vez por dia, e no qual as coisas ditas não serão mais unicamente determinadas pelas coisas a dizer (segundo uma necessidade absolutamente interior), mas pelo fato de que, uma vez por dia, se deverá dizer o tanto necessário para preencher tantas páginas? (ECO, 2001, p. 14).
}

Nas últimas décadas, vêm ganhando atenção os esforços pela elaboração da Teoria Multifatorial da Notícia, uma proposta de contemplação de todas as teorias anteriores como parciais e constituintes daquele que seria o primeiro verdadeiro paradigma da teoria jornalística. Elaborada pelo pesquisador português Jorge Pedro Sousa, ela questiona a eficiência das teorias anteriores como inseridas numa tendência "divisionista", que seria a de compartimentar excessivamente as unidades de influência sobre o processo de produção da notícia, e alinha-se com a tendência "unionista", que propõe um conjunto de explicações para o fenômeno "notícia". 
Sousa propõe o estudo da gênese e efeitos das notícias a partir de uma equação que consideraria as várias forças em ação: Força pessoal - as notícias resultam parcialmente das pessoas e suas intenções; Rotinas - elas decorreriam das práticas profissionais e organizacionais; Força social - as notícias são fruto das dinâmicas e dos constrangimentos do sistema social; Força ideológica - notícias são originadas por conjuntos de ideias que moldam processos sociais, proporcionam referentes comuns e dão coesão aos grupos; Força cultural elas seriam um produto do sistema cultural em que são produzidas; Força do meio físico em que são fabricadas; Força dos dispositivos tecnológicos disponíveis; e Força histórica: as notícias são um produto da história, durante a qual agiram as restantes forças que enformam as notícias que existem no presente. A história proporciona os formatos, as maneiras de narrar e descrever, os meios de produção e difusão, etc; o presente fornece o referente que sustenta o conteúdo e as circunstâncias atuais de produção. Ao ser simultaneamente histórica e presente, a notícia é sincrética. (SOUSA, 2004, p. 18)

Para Henn (2002, p. 15), “postula-se que o jornalismo comporta-se como sistema, já que possui elementos suficientes que evidenciam essa condição". Impossível não ceder à tentação de comparar a formulação teórica de um sistema jornalístico com o conceito de sistema literário desenvolvido, entre outros, por Antonio Candido (1976), e que serve, por analogia, aos nossos propósitos de sugerir uma definição mais ampla do que é "notícia". A teoria literária tem se ocupado, através dos tempos, não apenas em definir o que é "literatura", mas finalmente em admitir que "literatura" é um conceito relativo (nem nos atreveremos, neste momento, a ingressar na investigação sobre os limites entre texto literário e texto jornalístico!).

Para Candido, obra literária (que, dada nossa proposta analógica, poderia ser o jornal, ou cada um de seus elementos informativos), autor (que poderia ser o jornalista/editor) e sociedade interagem de tal forma que a própria questão de "autoria" se problematiza; o autor é produto da sociedade que o gerou, e essa mesma sociedade "recria" a obra pela forma como a recebe. $\mathrm{O}$ próprio autor é modificado pela obra que engendrou.

Portanto, fica claro que o conceito do que é notícia e de que efeitos ela causa - as grandes questões da teoria jornalística - depende em grande parte de como os jornalistas e a própria sociedade percebem a si próprios e ao fazer jornalístico, e que essas percepções não poderiam deixar de ser tingidas por causas sociais, culturais, históricas, ideológicas, etc. Compreender o campo jornalístico como sistema, como arena dialética de vários agentes, algo de que a própria teoria literária já se ocupou na pós-modernidade, admitindo a instabilidade e 
relatividade do que é literatura, é o que possibilitaria uma abordagem da tira como notícia, como unidade informativa que traz ao espaço do jornal, segundo algumas definições, "um relato integral de um fato que já eclodiu no organismo social” (MARQUES DE MELO, 2003); "um pedaço do social que volta ao social” (VOYENNE apud LAGE, 1992, p. 35-36); "uma representação social da realidade cotidiana, produzida institucionalmente e que se manifesta na construção de um mundo possível (ALSINA, 1996, p. 185).

Porém, essa abordagem sistêmica do jornalismo ainda não é hegemônica, e podemos identificar fortemente, vigentes na contemporaneidade, indícios do pensamento racionalista que fundamentou a autoimagem do jornalismo moderno, em seu compromisso com a verdade e a objetividade. Em Jornalismo, ética e liberdade, Francisco José Karam ocupa-se extensamente do aspecto ético e moral da notícia, afirmando: "é conveniente que conceitos como particularidade e universalidade sejam discutidos junto com o conteúdo normativo dos códigos jornalísticos" (KARAM, 1997, p. 93), como forma de contemplar diversas mundivisões no universo da informação institucionalizada. Porém logo a seguir, o autor revela professar uma perspectiva essencialmente racionalista em sua justificação filosófica da ética jornalística, ao afirmar:

Enfim, o que seria mesmo a Humanidade, sem os significados que ela erigiu? O que é mesmo o gênero humano, sem as relações que construiu e o diferenciam da animalidade pura ou do ente genérico Natureza? O que é mesmo o homem, sem a Razão que possibilitou a emoção, os sentimentos, as paixões, a noção mesmo de existência $^{12}$ ? (KARAM, 1997, p. 93).

Portanto, vimos que o potencial crítico está presente no jornal, mas ele não é tão estrutural nem tão prevalente como quer se supor. O jornal obedece a condicionamentos de agenda que engessam aqui e ali o fluxo crítico, e assim não devemos procurá-lo apenas no espaço mais óbvio do editorial ou das notícias tradicionais.

Se para Sousa notícia é “...o produto da interação histórica e presente (sincrética) de forças pessoais, sociais, (organizacionais e extraorganizacionais), ideológicas, culturais, históricas, dos meios físicos e dos dispositivos tecnológicos que intervêm na sua produção e através dos quais difundidas" (2005, p. 76), será que esse conceito não é aplicável, num sentido absolutamente amplo, a qualquer narrativa ${ }^{13}$ Não seria a tira capaz de trazer

12 Notar aqui a exclusão da possibilidade da senciência nos animais não-humanos.

13 Marshall McLuhan esboçaria tese análoga ao observar que o jornal não é só o que tradicionalmente se considera notícia, mas que o mosaico de informações que o constitui é u ma notícia por si: "O tema maciço da imprensa só pode ser examinado por contato direto com as estruturas formais do meio em questão. E é necessário declarar, de vez, que o "interêsse humano" é um termo técnico que designa o que é que acontece quando as muitas páginas de um livro ou os múltiplos itens informacionais são dispostos em mosaico numa 
"notícias" do que está se pensando, do que está se fazendo, do que está acontecendo na sociedade, inclusive contemplando a factualidade, que é um dos atributos da própria notícia, e, quem sabe, adiantando-se aos modelos tradicionais de "noticiar"? Para Terry Eagleton,

Pós-modernismo é um estilo de cultura que reflete alguma coisa dessa mudança de uma época, numa arte pluralista, superficial, descentralizada, infundada, autoreflexiva, divertida, derivativa eclética, que torna indistintas as fronteiras entre cultura 'alta' e 'popular', bem como entre arte e experiência cotidiana (1997, p. vii).

Embora o conceito de pós-modernidade encontre-se em cheque diante de pressupostos como os do filósofo e crítico cultural Gilles Lipovetsky, que propõe introduzir em seu lugar o conceito de "hipermodernidade" (GALLI, 2010) para caracterizar o contexto global contemporâneo marcado pela exacerbação das características atribuídas à modernidade, tais como o liberalismo e o individualismo, e ainda uma hiper-relatividade prevalente em todas as abordagens analíticas, cremos que especificidades da teoria da pós-modernidade referentes aos gêneros textuais ainda se aplicam a este estudo.

Portanto, se "arte e experiência cotidiana" já não têm fronteiras definidas, e se concordarmos em tomar os limites entre objetivo e subjetivo como difusos ou ao extremo, inexistentes, toda construção textual pode ser notícia, toda notícia pode ser obra literária, toda obra literária, ainda que a híbrida tira, pode trazer, ainda mais uma vez, "um relato integral de um fato que já eclodiu no organismo social” (MARQUES DE MELO, 1985, p. 49). O cânone, ou os cânones, se quisermos, perdem seu sentido referencial, inclusive no jornalismo, e assim, professando um modelo de pensamento alinhado à pós-modernidade como ferramenta para responder à indagação primordial do jornalismo - "o que é notícia" -, ainda que cientes das novas perspectivas que vêm sendo propostas em relação ao conceito de pós-modernidade, encerramos nossa argumentação.

\section{REFERÊNCIAS}

ADORNO, T.; HORKHEIMER, M. A indústria cultural: o esclarecimento como mistificação das massas. Dialética do esclarecimento. Rio de Janeiro: Jorge Zahar, 1985.

ALSINA, M. R. La construcción de la noticia. Barcelona: Paidós, 1996.

página. O livro é uma forma privada e confessional que induz ao "ponto de vista". O jornal é uma forma confessional de grupo que induz à participação comunitária. [...] O homem ligado ao livro tem a ilusão de que a imprensa seria melhor sem os anúncios e sem a pressão dos anunciantes. As pesquisas têm espantado até os diretores de jornais, ao revelarem que os olhos erráticos dos leitores de jornais se deliciam por igual com os anúncios e os textos noticiosos. [...] Anúncios são notícias.” (1971, p. 231-233) 
ANGELO, V. Um banheiro para laerte/sonia. Blogay, [S.1.], 8 fev. 2012. Disponível em: <http://blogay.folha.blog.uol.com.br/arch2012-02-05_2012-02-11.html>. Acesso em: 20 jan. 2014.

ASBURY, H. The gangs of new york: an informal history of the underworld. New York: Vintage Books, 2008.

CANDIDO, A. Formação da literatura brasileira (momentos decisivos) 1750-1836. São Paulo: Martins Editora, 1959. V. 1.

Literatura e sociedade. 5. ed. São Paulo: Editora Nacional, 1976.

CASTRO, A. Teorias do jornalismo, universidade e profissionalização. Biblioteca Online de Ciências da Comunicação, 2013. Disponível em: <http://www.bocc.ubi.pt/pag/castroalexandre-2013-teorias-jornalismo.pdf >. Acesso em: 13 fev. 2014.

CIRNE, M. A explosão criativa dos quadrinhos. 2. ed. [S.1.]: Vozes, 1977.

DICKENS, C. American notes for general circulation. [S.1.]: Buki Editions, 2009.

DORFMAN, A.; MATTELART, A. Para ler o pato donald - comunicação de massa e colonialismo. 6. ed. Rio de Janeiro: Paz e Terra, 2010.

EAGLETON, T. The illusions of postmodernism. Oxford; Malden, MA: Blackwell, 1997.

ECO, U. Apocalípticos e integrados. 6. ed. São Paulo: Perspectiva, 2001.

EISNER, W. Keynote address from the 2002 "will eisner symposium". ImageTxT

Interdisciplinary Comics Studies, 2002. Disponível em:

<http://www.english.ufl.edu/imagetext/archives/v1_1/eisner/>.

Five points neighborhood in new york city. About.com 19th Century History, [S.1.], [s.d.]. Disponível em: <http://history1800s.about.com/od/urbanconditions/p/fivepointsnyc.htm>. Acesso em: 13 fev. 2014.

GALLI, M. Gilles Lipovetsky: “a pós-modernidade não existe”. Revista Filosofia, ed. 49, Entrevista, 2010. Disponível em:

<http://portalcienciaevida.uol.com.br/esfi/Edicoes/49/artigo179777-1.asp>. Acesso em: 10 out. 2014.

HADJU, D. The ten-cent plague: the great comic-book scare and how it changed amer. [S.1.]: Macmillan, 2008.

HARVEY, H. C. Defining comics again: another in the long list of unnecessarily complicated definitions. The Comics Journal, [S.1.], 20 dez. 2010. Disponível em:

$<$ http://classic.tcj.com/top-stories/defining-comics-again-another-in-the-long-list-ofunnecessarily-complicated-definitions/>. Acesso em: 20 abr. 2014.

HENN, R. Os fluxos da notícia. São Leopoldo: Unisinos, 2002.

KARAM, F. J. C. Jornalismo, ética e liberdade. São Paulo: Summus, 1997. 
PROGRAMA DE PÓS-GRADUAÇÃO EM COMUNICAÇÃO DA UNIVERSIDADE FEDERAL DE SANTA MARIA

Laerte. Prêmio TRIPTranformadores 2013, [S.1.], 14 nov. 2013. Disponível em: $<$ http://revistatrip.uol.com.br/transformadores/site/homenageados/index.php?cod=92>. Acesso em: 20 jan. 2014.

LAGE, N. Ideologia e técnica da notícia. Petrópolis: Vozes, 1992.

MARQUES DE MELO, J. A opinião no jornalismo brasileiro. Petrópolis: Vozes, 1985.

MCCLOUD, S. Understanding comics. [S.1.]: Paw Prints, 2008.

RIZZINI, C. O jornalismo antes da tipografia. São Paulo: Companhia Editora Nacional, 1977.

SOUSA, J. P. Construindo uma teoria multifactorial da notícia como uma teoria do jornalismo. Biblioteca Online de Ciências da Comunicação, 2004. Disponível em: <http://www.bocc.ubi.pt/pag/sousa-jorge-pedro-multifactorial-jornalismo.pdf > . Acesso em: 14 fev. 2014.

Uma teoria multifactorial da notícia. Biblioteca Online de Ciências da Comunicação, 2005. Disponível em: <http://www.bocc.ubi.pt/pag/sousa-jorge-teoriamultifactorial-noticia.pdf>. Acesso em: 12 fev. 2014.

Uma história breve do jornalismo no ocidente. Biblioteca Online de Ciências da Comunicação, 2008. Disponível em: <http://www.bocc.ubi.pt/pag/sousa-jorge-pedro-umahistoria-breve-do-jornalismo-no-ocidente.pdf>. Acesso em: 12 fev. 2014.

WERTHAM, F. Seduction of the innocent. Revised edition ed. [S.1.]: Main Road Books, 2004.

\section{Original recebido em: 14/05/2014}

Aceito para publicação em: 18/02/2016

José Antonio Meira da Rocha

Mestre em Ciências da Comunicação - Concentração em Mídias, professor do Departamento de Ciências da Comunicação da UFSM/Frederico Westphalen

Liége Schilling Copstein Aluna do Mestrado em Letras - Literatura Comparada, Departamento de Letras da Universidade Regional Integrada do Alto Uruguai e das MIssões - URI

Esta obra está licenciada sob uma Licença Creative Commons. 